\title{
El Colegio Analizado desde Abajo: una Mirada desde los Estudiantes. Una Aproximación hacia las Instituciones Educativas Rígidas y Anómicas
}

\author{
Jerjes Loayza Javier
}

Universidad Nacional Mayor de San Marcos

Jerjes Loayza Javier es Licenciado en Sociología por la Universidad Nacional Mayor de San Marcos, Bachiller en Derecho y egresado de la Maestría de Sociología con mención en Estudios Políticos en la Universidad de Nacional Mayor de San Marcos. Investiga temáticas relacionadas a la cultura juvenil, publicando artículos en el Perú y el extranjero en torno a las tecnologías lúdicas, la violencia doméstica, la participación política y la educación. Actualmente investiga las resignificaciones de lo político en las simultaneidades juveniles.

Agradezco el financiamiento que recibí del Consejo Superior de Investigaciones, de la Universidad Mayor de San Marcos en el año 2007, como producto de ocupar el primer lugar del concurso de proyectos de Tesis a nivel de la facultad de Ciencias Sociales. Por otro lado, la investigación que aquí formulo, ha sido posible gracias al apoyo de diversas personas: a Tirso Molinari Morales, mi asesor de tesis, quien en todo momento con suma paciencia y dedicación estuvo a mi lado. A mis profesores: Mercedes Giesecke, Guillermo Nugent, Jaime Rios Burga y Cesar Agusto Espinoza. A Javier Vega, con quien tengo la suerte de debatir constantemente problemáticas sociales diversas. A Verónica Venturo por retroalimentar mi proceso elucubrador con sus opiniones y críticas diversas. A Manuel Loayza, de quien aprendí el placer de la constancia. A Consuelo Javier, quien me instruyó en la responsabilidad. A Jesús Loayza de quien emule el ímpetu por la creatividad. A toda mi familia por estar siempre conmigo. 


\title{
El Colegio Analizado desde Abajo: una Mirada desde los Estudiantes. Una Aproximación hacia las Instituciones Educativas Rígidas y Anómicas
}

\begin{abstract}
Resumen
Se propone en el artículo un análisis del mundo de la vida cotidiana de los alumnos, para comprender el impacto de los mecanismos educativos de la institución escolar en las interacciones juveniles y sus consecuentes resignificaciones. Dicha investigación se realizó en dos colegios ubicados en la comunidad autogestionaria de Huaycán, en Lima. Se encontrarán dos tipos de instituciones educativas. Por un lado la institución anómica que pierde el poder disciplinario sobre los alumnos, gracias a las estrategias de éstos para hacer del colegio un lugar libre, dentro de sus perspectivas lúdicas que no tienen mayor relación con fines académicos. Por otro lado se propone a la institución educativa rígida que, a diferencia de la anterior, dificultará la socialización de sus estudiantes gracias a su organización panóptica y rasgos totalitaristas. Ambos casos demuestran cómo los alumnos emplearían una serie de estrategias para desarrollar intenciones y emociones opuestas a las oficiales adulto - céntricas. Establecerían un mundo cotidiano con valoraciones propias, apartándose de cualquier tipo de presión escolar que pretenda cohibir ciertas interacciones lúdicas, todo ello en un contexto de pobreza y violencia doméstica.

Palabras clave: disciplina escolar, proceso de interacción educativa, adaptación del estudiante, delincuencia juvenil, autoridad del docente
\end{abstract}

\section{The School Analyzed from its Bases: A Student Perspective. An Approximation towards Rigid and Anomic Educational Institutions}

\begin{abstract}
In this article we propose an analysis of the world of the students' everyday life, to understand the impact of the mechanisms of the educational institution in the students' interactions and its subsequent resignifications. This investigation was carried out in two schools located in the community of Huaycan, in Lima. We propose there are two types of educative institutions. On the one hand we have an anomic institution that loses disciplinary power over the students, due to the students' strategies to make the school a fruitful place coherent with their ludic perspectives. On the other hand we have a rigid institution that will difficult students' socialization due to its panoptic organization and traces of totalitarianism. Both cases demonstrate how students will adopt a series of strategies to deliver different intentions and emotions, opposed to the adult-centric ones. They would establish an everyday world of their own values, independent of the vertical scholarity that inhibits their ludic ambitions, in a context of poverty and domestic violence.

Keywords: school discipline, educational interaction process, student adjustment, juvenile delinquency, teacher authority
\end{abstract}




\section{Definición de Objetivos}

$\mathrm{C}$ on esta investigación se busca comprender el impacto que generan los mecanismos disciplinarios y de control educativos, tanto desde los profesores como desde los auxiliares, en la vida estudiantil. Para ello se analizan las estigmatizaciones y estereotipos creados por éstos, y de qué forma interactúan dichos discursos y acciones sobre los estudiantes. Se exploran dos instituciones educativas, las cuales se caracterizan por tener índices de pandillaje polarizados. Una de ellas tendrá el mayor índice y la otra tendrá el menor índice de pandillaje. Las denominaciones con que se tipifican ambas instituciones parten de la comprensión de las valoraciones estudiantiles. En resumen, se exploran las prácticas e imaginarios estudiantiles para la interpretación de realidades educativas que se diferencian no sólo en sus resultados, sino en las tecnologías que emplean para educar a los alumnos.

\section{Orientaciones Conceptuales}

Los supuestos teóricos son los siguientes: la complejidad, para comprender los diversos fenómenos sociales que se suscitan en los actores, es producto de un mundo social que muestra una estructura multiforme (Schütz, 1993). La riqueza de los resultados de la investigación se halla en lo que Morin (1999) designaría como complejidad organizacional y no en su materia constitutiva. El ejercicio exploratorio desarrollado plantea actores socialmente moldeados y, al mismo tiempo, vitalmente constructores de su realidad social desde esa particular visión que se cristaliza simbólicamente en la interacción y que influye así en sus relaciones sociales (Molinari, 2002). A través de la teoría interaccionista se podrá comprender la capacidad del estudiante para escoger alternativas al discurso educativo o al menos para intentarlo, por lo cual el concepto de gestión será clave: la persona gestiona su vida (Guasch, 2002). Dos autores son importantes para la comprensión de los actores en su constante interacción: Mead (1990) y Goffman (2001). La fenomenología, por su parte, permitirá ir más allá de una perspectiva explicativa, para aproximarse a la comprensión desde el mundo de la vida de los actores. Lo que hará peculiar al mundo de la vida es que se refiere al mundo percibido por el ser humano en la actitud natural, y no por el científico (Martín, 1993). 
La investigación concibe las interacciones estudiantiles clandestinas fuera del discurso educativo oficial como una alternativa desde la óptica de sus protagonistas, de su "yo", del "nosotros" que busca un espacio dónde desenvolver y desembocar su expresividad (Mead, 1990). Para ello se establecerá un mundo "nosotros", integrado por los diversos mundos de la vida juvenil estudiantil, y un mundo "ellos", integrado por profesores, auxiliares y demás autoridades educativas. Si bien se pueden vislumbrar mundos "nosotros" y mundos "ellos" al interior de los propios estudiantes o de las autoridades educativas, el cisma existente entre los empoderados educativos y los dirigidos es patente y significativo. En este mundo "nosotros" el período de margen o de liminalidad transicional (Turner, 1970) será un estado por el cual el estudiante deberá decidir, aprender y experimentar a través de múltiples matices y resignificaciones.

En cuanto al marco teórico para comprender las instituciones educativas, las consideraciones de Foucault (2004) permiten comprender el sometimiento institucional educativo más allá de la coacción física, un tipo de sometimiento que no se obtiene solamente por la violencia. La disciplina educativa podrá obrar sobre elementos materiales y a pesar de todo eso no ser violento; será calculador, organizado, técnicamente reflexivo, sutil, y sin embargo permanecer dentro del orden físico. Esta tecnología estará compuesta de elementos y de fragmentos, utilizará herramientas y procedimientos inconexos, a pesar de la coherencia de sus resultados no será sino instrumentalización multiforme. Las instituciones educativas rígidas recurrirían a ellas, utilizando, valorizando e imponiendo algunos de sus procedimientos: se trata de una microfísica educativa del poder. En esta microfísica, el poder se concibe como estrategia (y no propiedad). A los estudiantes se les vigilará, se les educará y se les corregirá. Estamos ante un poder disciplinario que se debe al uso de instrumentos simples: la inspección jerárquica, a través de una serie de tecnologías múltiples y entrecruzadas. Por su parte Goffman (2001) propone en las instituciones totales características que se asemejan a las ambiciones de una institución educativa rígida. Ésta buscará en todo momento fabricar nuevos individuos mediante procesos de despojo y un sentimiento de culpa constante. Se propiciará la pérdida de autodeterminación, prevaleciendo siempre el sistema jerárquico y autoritario educativo, logrando la sumisión mayoritaria en los alumnos, quienes caen en un sentimiento de desposeimiento.

Por el contrario, una institución educativa anómica no llega a establecer ese tipo de relaciones con los alumnos debido a la carencia de autoridad ante éstos. Esta anomia será evidente en el rechazo manifiesto a las normas institu- 
cionales. Merton (1992) explica la anomia como producto de cierto estado de confusión en el que un grupo se encontraría sometido al antagonismo entre sistemas de valores, que pululan liminalmente entre el discurso institucional educativo y los discursos de estudiantiles juveniles. Ello produce cierto grado de inquietud y la sensación de separación de la institución educativa, de su credibilidad y su legitimidad. Sin embargo esta anomia no se vuelve aguda, al punto de la desintegración de los sistemas de valores que daría por resultado angustias pronunciadas. Ello se debe por un lado a que los estudiantes poseen sus propias valoraciones etarias y grupales; por otro lado, estas creencias y discursos no están escindidas de lo oficial y aceptado en la vida institucional educativa, sino que conviven de forma liminal, es decir inter estructural. De este modo el grado en que la tradición, las costumbres y los controles institucionales están eficazmente unificados con los objetivos que ocupan un lugar elevado en la jerarquía de los valores instituidos, como indica Merton, no es del todo logrado, pues los objetivos de los estudiantes son diferentes de los que la institución educativa desearía de ellos y los controles institucionales no poseerán, por ello, suficiente poder sobre ellos.

\section{Metodología}

Se utilizó el modelo conceptual inductivo, debido a que la investigación es de naturaleza exploratoria, insertándose en un proceso de descubrimiento que parte de la observación a los datos, luego a la hipótesis y finalmente la teoría (Mejía, 2003). Se trata de un ejercicio exploratorio de actores socialmente moldeados y, al mismo tiempo, vitalmente constructores de su realidad social desde esa particular visión que se cristaliza simbólicamente en la interacción y que influye así en sus relaciones sociales (Molinari, 2002).

La investigación se realizó en dos colegios de educación pública. Si bien las denominaciones, tanto de colegio rígido como anómico se adoptaron una vez realizado el trabajo de campo, las condiciones a priori para elegir los colegios se pueden ver en la Tabla 1.

Se utilizaron estrategias metodológicas cualitativas. Entre las técnicas de investigación elegidas está la observación participante, la cual refiere una forma específica de investigación de campo en la que el investigador toma parte como actor de los acontecimientos que estudia (Maffesoli, 1993). Se presenciaron clases estudiantiles al interior del colegio, momentos lúdicos como los partidos de fútbol, vóley, recreo, etc. Al haber siempre un modo de 


\section{Tabla 1}

Características de los Colegios Elegidos

\begin{tabular}{|c|c|c|c|c|c|}
\hline Colegio & Ubicación y Riesgo & $\begin{array}{l}\text { Cantidad de } \\
\text { alumnado }\end{array}$ & $\begin{array}{l}\text { Riesgo y violencia } \\
\text { (categoría } \\
\text { de mayor } \\
\text { importancia) }\end{array}$ & $\begin{array}{c}\text { Discurso } \\
\text { institucional }\end{array}$ & Estigmatización \\
\hline $\begin{array}{l}\text { Institución } \\
\text { educativa } \\
\text { anómica }\end{array}$ & $\begin{array}{l}\text { Zona de alta } \\
\text { peligrosidad. En } \\
\text { los alrededores se } \\
\text { producen luchas } \\
\text { callejeras entre } \\
\text { pandillas. }\end{array}$ & $\begin{array}{l}\text { Un } \\
\text { aproximado } \\
\text { de } 4000\end{array}$ & $\begin{array}{l}\text { Desde el punto } \\
\text { de vista de los } \\
\text { pobladores, } \\
\text { tiene la mayor } \\
\text { cantidad de } \\
\text { estudiantes } \\
\text { pandilleriles. }\end{array}$ & $\begin{array}{l}\text { Discurso } \\
\text { formal } \\
\text { educativo } \\
\text { nacional. }\end{array}$ & $\begin{array}{l}\text { Considerado por los } \\
\text { pobladores como } \\
\text { uno de los colegios } \\
\text { peor organizados } \\
\text { de Huaycán. }\end{array}$ \\
\hline $\begin{array}{l}\text { Institución } \\
\text { educativa } \\
\text { rígida }\end{array}$ & $\begin{array}{l}\text { La zona no tiene } \\
\text { la peligrosidad de } \\
\text { otras zonas, sin } \\
\text { embargo no deja } \\
\text { de ser peligrosa } \\
\text { durante las } \\
\text { noches. }\end{array}$ & $\begin{array}{l}\text { Un } \\
\text { aproximado } \\
\text { de } 800\end{array}$ & $\begin{array}{l}\text { Considerado con } \\
\text { el menor índice } \\
\text { de pandillaje. }\end{array}$ & $\begin{array}{l}\text { Discurso que } \\
\text { privilegia } \\
\text { en la fe y } \\
\text { los valores } \\
\text { religiosos y } \\
\text { éticos. }\end{array}$ & $\begin{array}{l}\text { Elogiado por la } \\
\text { población gracias } \\
\text { a su organización } \\
\text { efectiva, siendo } \\
\text { parte de una amplia } \\
\text { red educativa en } \\
\text { el país. }\end{array}$ \\
\hline
\end{tabular}

interactuar con los otros y de acceder al nicho cultural ${ }^{1}$, se buscó superar la condición de forastero ${ }^{2}$ del investigador. Se decidió encarnar a un encuestador informal que no tenía nombre ni institución definida, siendo un joven sin mayores ambiciones que las de conversar en las inmediaciones de un colegio. Se utilizó asimismo entrevistas a profundidad, que buscaron que el estudiante exprese libremente sus motivaciones, creencias, sentimientos, estilos de pensamiento, imaginarios y concepciones ligadas a su vida cotidiana. La entrevista se realizó con un cuestionario semi estructurado, sin preguntas totalmente definidas, porque ello conllevaría a cerrar el habla, convirtiéndose en un enrejado unidimensional (Ibañez, 1986). Fueron un total de 10 entrevistas para cada sexo en el colegio de mayor alumnado y 5 entrevistas para cada sexo del colegio de menor alumnado. Se entrevistó a 5 docentes en cada colegio. Asimismo a todos los auxiliares ( 6 en total) en el colegio de mayor alumnado y al único auxiliar del colegio de menor alumnado. La muestra alcanzó el

1 Tal nicho cultural puede ser el de persona adoptada, el de huésped o incluso el de enemigo. (Guasch, 2002).

2 Para Shütz (1974) el forastero que visita por vez primera un determinado ámbito de investigación, es un hombre "sin historia", que podrá sólo acceder al presente y futuro del grupo como máximo, pero jamás al pasado. 
punto de saturación gracias a la ayuda de algunos auxiliares y profesores que facilitaron la elección de los alumnos, de acuerdo a sus tipologías y características. Los estudiantes elegidos para la investigación tenían entre 13 y 17 años y eran del turno mañana y turno tarde en la institución educativa anómica, y del turno tarde en la institución educativa rígida, debido a que allí sólo existe un turno. La naturaleza exploratoria propuesta permitió detectar rasgos y tendencias de mentalidad colectiva en el pensamiento y en las actitudes de jóvenes socialmente representativos de Huaycán.

El trabajo de campo fue realizado en nueve meses. Las visitas fueron de tres días a la semana como mínimo. Se crearon relaciones amicales con alumnos y alumnas. Es aquí donde merece especial atención el etnométodo. Éste se refiere a la lógica de sentido común que utilizan cotidianamente los actores, que les permiten vivir juntos, incluyendo a la particularidad de sus conflictos, y que rigen las relaciones sociales que mantienen (Coulon, 1998). Se buscó en todo momento tener consigo una importante suma de espontaneidad garantizando en todo momento una relación en la que el interlocutor se explaye en una diversidad de temas que a veces parecería apartarse de los objetivos, pero que permitían enrumbarse paulatinamente a las preguntas en un diálogo complejo, que buscaba por encima de todo otorgarle una naturalidad cotidiana a la conversación. Se pudo recoger información muy rica y diversa que abarcó todas las distinciones y diferenciaciones de clandestinidad gracias a la indexicalidad empleada en todo momento. Ésta se refiere a todas las circunstancias que rodean a una palabra, a una situación (Coulon, 1998).

Encontrar el momento indicado y el lugar indicado son dos circunstancias esenciales a considerar. En un inicio las autoridades educativas aconsejaron utilizar un aula para hacer las encuestas y entrevistas, pero ello habría significado un enclaustramiento del individuo. Las aulas, al poseer una carga emocional negativa para el alumno, impedían un clima de confianza. Se prefirió encuestarlos en el patio, permitiendo que el entrevistado elija el lugar exacto. El momento indicado para las entrevistas era por lo general el curso más "aburrido" para ellos, de este modo las encuestas y entrevistas significaban una salida del "aburrimiento", relajarse y olvidar las tensiones en un momento catártico. Cada pregunta propuesta buscó compartir una historia, una anécdota, una aventura, un pequeño secreto que despierte risas e introspección en ambos.

El poblado elegido para la investigación fue la comunidad autogestionaria de Huaycán, la cual cuenta con más de 60000 personas, ubicada en la ciudad de Lima; esta comunidad nació en medio de la violencia política, por lo que fue 
marcada en sus inicios y en su constitución por Sendero Luminoso, que dejó un rastro de violencia estructural en la comunidad, provocando una situación constante de miedo e inseguridad. A ello se le suma la violencia doméstica y la pobreza que asolan a las familias. Asimismo es una comunidad que posee un alto índice de delincuencia juvenil, y que según sostienen sus pobladores, encuentran en las pandillas la peor amenaza. En la investigación se evitó en todo momento idealizar a la comunidad de pares como si se tratara de una instancia de socialización impoluta, transparente, de buenas voluntades, y a su vez se evitó satanizarla.

\section{Discusión de Resultados}

A continuación se explicitarán los resultados a partir de la identificación exploratoria de dos instituciones educativas, la anómica y la rígida. El primer eje de análisis serán los estudiantes y sus respectivos mundos de la vida. Asimismo se analizará cómo la anomia y la rigidez institucional educativa en cada colegio influyen en los mundos de la vida estudiantiles. Finalmente el tipo de interacción estratégica será un eje importante para comprender los discursos y comportamientos estudiantiles y su relación con los discursos educativos respectivos.

\section{El Caso de la Institución Educativa Anómica}

Dicha institución alberga cerca de 4000 alumnos. El nivel académico secundario está dividido en dos turnos, cada uno de ellos posee un total de cinco aulas por grado académico. Sobre el colegio recae un estigma muy remarcado: en su mayoría los alumnos son vistos por la comunidad como pandilleros.

Los pandilleros se ocultaban muy bien entre el alumnado, siendo necesario el uso de informantes claves para su identificación por parte de las autoridades. Ello otorgaba una gran pista, no eran pandilleros ordinarios o unos transgresores típicamente reconocidos, eran alumnos que sabían cómo actuar en determinados contextos y de los cuales se tenía diversas noticias de faltas fuera del colegio. Esta facilidad de contextualizar su comportamiento se debería a la interiorización de valores y normas contradictorias entre sí-la del colegio y la familia y la de los pares pandilleriles. Así, estos jóvenes se servían de lo que Recasens (1999) denominó comportamientos situacionales: unos para el ámbito en donde rigen la presión y el control social, y otros para 
el vecindario y entornos subrepticios de pares. Para comprender las diversas interacciones que suscita el espacio institucional del colegio estatal, es necesario verlo desde tres mundos de la vida cotidiana, los cuales no dejan de relacionarse constantemente: el de los profesores, el de los auxiliares y el de los alumnos. Cada uno de éstos posee una complejidad que multiplicaría sus mundos de la vida.

Mundo de la vida de los profesores en interacción con los alumnos. La institucionalidad educativa se caracteriza por docentes que establecen una relación vertical con los alumnos. Foucault (2004) hablaría de cierto monopolio del conocimiento en el que tanto el dictado de clases como la evaluación no permiten legitimar al alumno a tomar el sitio del maestro una vez aprobados los exámenes: se administra conocimiento ininterrumpidamente. La institucionalidad educativa tiende, así, a establecer un poder simbólico, una relación maestro - discípulo basada en un poder fáctico al momento de colocarles una calificación, por lo que no necesitaría emitir signos de su potencia, ni imponer por la fuerza una marca a sus sometidos, los mantiene en un mecanismo de objetivación (Foucault, 2004).

Sin embargo en el colegio objeto de investigación no siempre el profesor puede desarrollar dicho poder en el aula, y menos aun cuando no ha sido mínimamente legitimado por los alumnos, que demuestran una gran capacidad adaptativa ante la adversidad de situaciones. Por ejemplo, en el caso del taller de ebanistería el profesor ha perdido la facultad de calificar a los alumnos ante el chantaje que estos le imponen, siendo por ello el taller de hombres el que cuenta con más evasiones: de un total de 20 alumnos, apenas ingresan a las prácticas aproximadamente 5. Los evasores utilizan su tiempo libre para jugar fútbol en horas de clase o deambular sin rumbo por los patios de la escuela buscando pares con quienes establecer un diálogo. Esto no se debería solamente a la carencia de recursos económicos para comprar materiales, sino a una forma de evadir responsabilidades y generarse oportunidades lúdicas, fuera del sofocante claustro que puede representar un aula o bajo la vigilancia de un profesor para un alumno.

El respeto es tan austero que el profesor debe defenderse de las agresiones verbales de sus alumnos respondiendo en el mismo tono: una agresión se responde con otra agresión, retroalimentando el proceso de conflicto entre ambos. En este contexto, la enseñanza de un oficio es difícil tanto para el profesor como para un alumno. Éste quiebra el lineal y monótono horario escolar, abandonando las aulas para acudir al patio. El último recurso del pro- 
fesor sería desaprobarlos, que es el único bastión que le otorga poder sobre los alumnos, con lo que los alumnos se sentirían en la obligación de obedecer. Pero la respuesta de un alumno es difícil de rebatir: el alumno chantajearía al profesor, acusándolo de pedirle dinero, el cual se justificaría en la compra de materiales para el curso. Para evitar malentendidos con padres de familia o con directivos, el profesor muchas veces aprobará al alumno.

En el caso del taller femenino de costura y vestido, las alumnas dejan de participar haciendo alusión a su impedimento económico. Son 17 las alumnas en el taller e ingresan apenas 5, el resto evade el curso. Existen casos más extremos de evasión en este taller: para no perder la oportunidad de aprovechar las clases, las alumnas piden al auxiliar permiso para ir a comprar los materiales en algún mercado cercano. Regresan al colegio apenas media hora antes del fin de las clases, sin haber comprado nada, con el pretexto de no haber encontrado lo que la profesora del curso les pedía. Tanto hombres como mujeres crean una forma de reforzar las relaciones con sus pares y evitar enfrentar la realidad de talleres que les obligaría a pensar sobre qué harán en un medio laboral tan caótico e injusto como el de Huaycán.

En una sección del primer año de secundaria del turno tarde, en una de las aulas más problemáticas para los profesores, los alumnos administran en diversas ocasiones el manejo de ésta. El menosprecio por el curso y por el profesor es muy claro, siendo nulo el poder del docente sobre los estudiantes. Las calificaciones que antaño le otorgaba un manejo sobre ellos, pierde su valor una vez más. A los estudiantes les importa más sus actitudes lúdicas junto al resto de pares, así como disfrutar de las distracciones ajenas al curso burlándose del profesor. El profesor es consciente de esta situación y de una forma tácita no se enoja, hace su trabajo calmado, no les presiona para que aprendan. Los alumnos, enterados de esta actitud, tampoco excederán sus actitudes en clase, existiendo una especie de acuerdo entre ambas partes. Acudimos al descentramiento de la producción de conocimientos, antes ejercida por padres y maestros, quienes eran la fuente del saber y del conocimiento del mundo, cumpliendo la función de interpretarlo y hacerlo inteligible para los hijos (Macassi, 2001). La autoridad del profesor es apenas superficial, ha perdido el control sobre los alumnos, sólo desea finalizar la clase sin mayores inconvenientes. Por su parte los alumnos generarán para sí espacios de entretenimiento, alejados de un aula que los cohíba, de un profesor al cual no respetan y de un curso al cual han perdido interés, en el caso de que alguna vez lo hayan tenido.

La evasión no significa que los alumnos declaren su molestia por tener 96 I profesores que los aburran o a los cuales no respeten, muy por el contrario les 
agrada una situación en la que se sientan empoderados. Algunos de los profesores recurrirán a los golpes ante la imposibilidad de controlar a los alumnos. Su misión como profetas del conocimiento se desvanece, la relación con los alumnos es puramente de compromiso tácito, de un transcurrir de las horas en el que los profesores lo toman tranquilamente, resignados a cumplir con los compromisos académicos sin enojarse con casos aparentemente perdidos, o descargan sobre los alumnos su impotencia, y los persiguen con una correa o los golpean con objetos tales como una regla o un puntero -transformando la dimensión didáctica de esos objetos para convertirlos en armas de violencia física. Así, sus clases no cumplirían, en su mayor parte, con el objetivo institucional de educar. Los alumnos dividirán a los docentes en dos tipos. Por un lado los "criticones" ${ }^{3}$, que les exigen y les desean imponer un estilo de hacer las cosas, los que les gusta "gritar por las huevas"4, que los golpean y amenazan. Por otro lado, los "chéveres" que ayudan a aprobar a los alumnos, que no les exigen demasiado porque desde su perspectiva sostienen que perderían el tiempo o que les implicaría un desgaste de energías muy grande. Existen alumnos que debido a esta situación sufren la anomia que acarrea un aula sin un profesor legitimado en su función.

Mundo de la vida de los auxiliares y su relación con los alumnos. A la relación entre profesores y alumnos se le debe sumar la no menos importante relación con los auxiliares. A diferencia de los profesores, los auxiliares construyen una relación de poder diferente, ellos no tienen conocimiento que impartir, su rol se limita a que estén en un perfecto estado de orden y disciplina, aun a costa de la violencia física. Su monopolio no es más que del orden, a diferencia del profesor quien además administra conocimiento. Hay todo tipo de formas de emitir su signo de poder, que tiene cierta tendencia a percibirse como un rol carcelero de escuela secundaria. Uno de ellos bautizó a una vara de madera de 50 centímetros como "panchito", haciendo alusión indirecta al órgano viril masculino. La dimensión fálica que toma este objeto le otorga mayor poder, y más aun al provenir de un hombre, que impone la disciplina a través de la violencia masculina con fines institucionales.

Existen los auxiliares que imponen su poder a través del miedo. Aquel que lleva consigo una inmensa regla administra el orden institucional vía una herramienta educativa, transformada en una tecnología que "corregirá" a los

3 Categoría propuesta a partir de los testimonios literales de los alumnos.

4 Obtenido de una entrevista a profundidad con un alumno del cuarto año de secundaria. 
alumnos. Por otra parte están los auxiliares que renuncian a un signo para imponer su poder. En esta tipología tenemos el caso de una auxiliar femenina, cuyo poder radica en su hermetismo, ya que a diferencia del resto de auxiliares no otorga ninguna concesión a los alumnos. Este hermetismo se ve alimentado de los prejuicios estereotipadores con que trata a los alumnos, radicalizando su opinión acerca de ellos. Justifica su actitud en no otorgar confianza alguna a los alumnos ya que considera que éstos perderían el respeto hacia ella, provocando la caducidad del auxiliar en el manejo del poder disciplinario. Los jóvenes estudiantes son estereotipados como carentes de una iniciativa propia, al querer que "todo se les haga"; a los ojos del auxiliar son incapaces de solucionar sus propios problemas, incluyendo ánimos de resiliencia. Tal perspectiva deja de lado la capacidad de los alumnos por formular una serie de salidas a la opresión educativa que ellos sienten sobre sí, resignificando su propio mundo a pesar del contexto desalentador, prueba de ello es la "evasión".

Los auxiliares son ajenos al mundo personal de los alumnos, sin embargo uno de los auxiliares, en claro contraste con el resto, posee una cercanía hacia la vida cotidiana de los alumnos, convirtiéndose en un agente de socialización ambiguo. A diferencia del resto, es capaz de ser amigo de los alumnos y alumnas, irónico y duro a la vez con ellos. A sabiendas de que algunos alumnos escapan de los talleres, o que tienen un sinnúmero de pretextos para revolotear por el patio, el auxiliar les presta la radio y les permite que estén en un pequeño auditorio, ya que en cierta ocasión un alumno había golpeado con un tubo metálico a otro compañero (ambos formaban parte de un grupo de adolescentes del segundo grado de secundaria que deambulaban por los patios sin tener que hacer); este tubo sólo arañó la frente del alumno: siendo consciente de la culpa que tendría dicho auxiliar, por estar aquellos alumnos a su cuidado y a sabiendas del descontrol en el que caen muchas veces, propone soluciones a corto plazo que permitan neutralizar la liminalidad violenta en los alumnos.

Facilita su trabajo otorgando a los alumnos ciertas posibilidades, pero no las suficientes para que hagan lo que quieran. En una ocasión alentó a un grupo de evadidos 5 a que jueguen fútbol ${ }^{6}$. Este auxiliar es consciente no sólo de las constantes prácticas de violencia y astucia estudiantil. Es consciente 
de sus límites como autoridad educativa, así como de la necesidad de ceder a ciertas prácticas típicamente juveniles que proporcionen a los alumnos un marco de libertad de acción. En una ocasión un colega de otras secciones le advirtió que dos alumnos estaban peleándose, a lo que el auxiliar contestó "iEstamos en la semana de la juventud, se han pegado pe! ¿Y?”. Sabe otorgar y ceder frente a la indiferencia de otros profesores y la dureza de algunos auxiliares. La interacción de significaciones entre este auxiliar y sus alumnos es muy rica en lenguajes y gestos simbólicos, utilizando una serie de palabras y frases típicamente juveniles, que ellos comprenden y que las interpretan como de su propio mundo de la vida. Posee una serie de códigos que le sirven para ganar la colaboración de sus alumnos. Empleará sobrenombres y adjetivos como "papi" o "mami", dependiendo de qué sexo sea el alumno. De una u otra forma, evita en todo momento llamarlos por sus apellidos, que tendría dos consecuencias en el mundo de la vida de los alumnos: por un lado les quita su individualidad y particularidad, al llamarlos por un apellido que a la vez es el de su padre, y por otro lado, no es objeto de identificación por parte del joven estudiante, llamado por sus pares con sobrenombres que sirven para ser rebautizado por el grupo, hilvanan una nueva simbología de identidades a partir de significaciones diversas.

Mundo de la vida de los alumnos y comportamientos. En una ocasión a un grupo de alumnas del turno tarde las retuvieron para recriminarles que no debían ir al colegio con faldas tan cortas. Ellas manifestaban que el no tener dinero implicaba usar la misma falda año tras año. Los profesores y auxiliares nada podían decir ante la pobreza y la austeridad de Huaycán. Las alumnas, capitalizando esta situación, no fueron castigadas. Este es un caso de discursos amparados en la situación socio-económica como pretexto a ciertas actitudes fuera de la permisividad institucional educativa. A continuación se explican situaciones en que el rigor institucional es doblegado.

Evasiones: al margen del margen. La institucionalidad del colegio había decaído de tal modo que su normatividad tenía ínfima legitimidad para un gran porcentaje de alumnos, los cuales salían del aula sin permiso alguno. Esta evasión se convertiría en un comportamiento liminal institucionalizado: estar en el colegio, en sus dominios, bajo su autoridad, y a la vez no estar en él, al salir de sus aulas adueñándose del patio, lugar de tránsito. En síntesis, una situación en la que se deja entrever su carácter de liminalidad inter 
estructural. No es un simple pasatiempo, es una declaración de desacuerdo con el curso al cual han renunciado simbólicamente; representa construir un tiempo propio, con sus lenguajes y estilos. No evaden al curso por la dificultad que éste represente, lo evaden por el aburrimiento y el inconformismo que tienen hacia él?

"Naturaleza chonguera". A la pregunta ¿qué era lo que más le atraía del colegio? la mayoría de entrevistados indicó que el colegio poseía una característica que lo hacía único, era "chonguero". Aquello era sinónimo de diversión, de amistad, de juego. Para entenderlo se debe comprender las diferentes satisfacciones de los alumnos y alumnas de esta institución. A diferencia de otras instituciones educativas, algunas alumnas aducen que en aquel colegio nadie se ufana de sí mismo como mejor que el resto. Ello se debería principalmente a la ausencia de los padres de familia, quienes debido a la necesidad apremiante de recursos económicos, dejan a sus hijos solos, los cuales privilegiarán de este modo la amistad de los pares antes que la relación con sus padres. Los estudiantes sufren problemas similares y están bajo la institucionalidad de un colegio que se desmorona en beneficio de las actitudes clandestinas de los propios alumnos. Éstos no imponen su status o valía simbólica individualmente frente a los demás, al menos no de manera que pueda provocar la ira del resto. Se trata de una identificación muy grande con el colegio, el cual hace las veces de equivalente funcional de un hogar idealizado y/o del grupo amical, por ello quieren mucho a dicha institución educativa, porque esa "gente", sus amigos y compañeros, es preferible a cualquier otra: claro caso de socialización horizontal, antes que vertical. La socialización vertical exigiría obligaciones que una institución deslegitimada no es capaz de imponer. Es decir, tanto la precaria institucionalidad escolar como la precaria racionalidad formal son tales que la condición escolar de "grupo secundario" casi se diluye en aras de una prolongación de los grupos primarios extraescolares.

En casa, los alumnos tendrían obligaciones que cumplir. En el colegio pueden capitalizar un amplio tiempo libre, convirtiéndose en un espacio de relajamiento en donde construyen junto a sus nuevos compañeros estilos de continua renovación lúdica: el "chongo". Un discurso se repite continuamente, "me permite ser libre", pues la actitud disciplinaria precaria por parte de profe-

7 Por ejemplo, diversos alumnos y alumnas habían repetido el año escolar por cursos de pocas horas académicas, como Arte o Religión. Cursos como Matemática o Lenguaje eran aprobados por la mayoría de alumnos. 
sores y auxiliares otorga a los alumnos posibilidades ilimitadas por encima de una gran parte de profesores. Ensayan un control relativo sobre los auxiliares, en donde funcionan actitudes más negociadoras y una declarada apropiación sobre el espacio escolar, al que bautizan continuamente como un espacio "clandestino". Se podría decir que los alumnos logran arrebatarle parcialmente al colegio el monopolio de la acción y del conocimiento legitimado, irrogándose ciertos espacios y capacidades de poder. Esto les permite un margen de lo que ellos denominan como "libertad". A esta situación se le añade la solidaridad colectiva entre los estudiantes, quienes jamás se acusarán mutuamente por alguna falta cometida. Ésta puede radicar en pintar paredes con escandalosos colores, de dimensiones muy grandes; a pesar de ello ninguna autoridad sabrá quién fue el responsable. Esta solidaridad se consigue bajo dos argumentos, o bien responde a una fidelidad al grupo del cual se forma parte, al menos de modo indirecto, o bien por miedo a las represalias de los acusados. Sea cual sea el argumento, a la larga se convierte en una importante regla a seguir por los estudiantes. Para concluir, el ser "chonguero" permite comprender la complejidad con que estos estudiantes logran arremeter contra el poder institucional, deslegitimándolo, recreando así sus propios significados. Representa un claro contraste al conformismo y a la mera pasividad que se le acuña a la juventud. Por ello, al "normal nomás" que se decía que caracterizaba a la juventud en los noventas (Cánepa, 1990), le oponemos el estadio "chonguero", que refleja una clara posición de valores y actitudes en relación directa con sus necesidades, ambiciones y expectativas acordes con las especificidades y códigos de los mundos de la vida juveniles.

Estigmas. La estigmatización que existe sobre el colegio puede significar para algunos estudiantes un orgullo: pertenecer a un colegio "chonguero" y del cual surgen los miembros más connotados de las pandillas nos explica cómo algunas alumnas y alumnos beben alcohol con el buzo escolar. Se convierte en un signo de poder que les otorga seguridad frente al resto de pobladores que tiende a estigmatizar al colegio como el de mayor índice de alumnos en riesgo. En efecto, un atributo que estigmatiza a un tipo de poseedor es capaz de confirmar la normalidad de otro y por consiguiente, no es ni honroso ni ignominioso en sí mismo (Goffman, 1990). Sin embargo existe otro grupo de estudiantes, también numeroso, que si bien puede sentirse a gusto en el colegio, siente la vergüenza de ser tildado con los mismos apelativos al utilizar el mismo buzo que utilizan aquellos otros que se jactan de ser portadores de liminalidad muchas veces violenta. El buzo es símbolo de desconfianza por 
quién lo posee, por ello el auxiliar replicaba "icon el uniforme nada malo!". Un caso que conmovió a la institución educativa y salió a la luz en medios de comunicación, fue el de un grupo de alumnos que celebraban en un hostal. Se puede constatar que la gran falta en este caso no fue el hecho en sí, sino el haber dañado la imagen institucional debido al buzo que exteriorizaba su afiliación educativa. El buzo guarda significados diferentes tanto para el discurso formal institucional, como para los mundos de la vida de los alumnos. En éstos, un grupo de estudiantes capitalizará a su favor el estigma que recae sobre ellos, y otros huirán del estigma, porque les provocaría sentimientos de inferioridad y culpabilidad.

El caso más representativo de la tensión que puede generar el estigma sobre un sujeto lo tenemos en un importante discurso: "algunos dicen que aquí estudia sólo carachosos, iaquí hay puro piraña, paran diciendo!" 8 . De esa forma se generaliza a su alumnado como "pirañas", apelativo que significa el ser adolescentes con sólo deseos de robar y que provienen de familias sin padres, abandonados a su destino. Se les dice también "carachosos", un claro adjetivo estigmatizador, al tener como significado a sujetos con enfermedades epidérmicas y con peligro de contagiar de sarna al resto. Los estudiantes interiorizan este adjetivo al criticar lo sucio que es su colegio, no sólo por la limpieza comúnmente conocida, sino la limpieza simbólica en sus alumnos. En esta perspectiva, un auxiliar sostendría que el gran problema de los alumnos que tiene a su cargo es que "todos se contagian"; este estigma se trataría de una especie de enfermedad contagiosa contra la cual no existe vacuna ni forma de escapar, a no ser que se viva fuera de Huaycán. El contagio al cual se alude podría ser interpretado como las redes clandestinas que son asumidas ya sea activamente o pasivamente por los alumnos en la institución educativa. Acudimos a un nihilismo que niega cualquier forma de solución al haber heredado estructuras históricas infames.

Para otros alumnos, el estudiar en aquel colegio "paltea" ${ }^{9}$, debido a cierta "relajación" del cuerpo y la mente, lo que explica cómo se pierde el horizonte académico y de ambiciones educativas debido a los referentes en el colegio. Esta emulación no sería posible sino gracias a la iniciativa de los propios estudiantes, quienes hacen más tolerable un mundo de la vida que se caracteriza por la violencia doméstica, por la pobreza y por la verticalidad educativa. Así, 
este colegio se transforma a los ojos de los alumnos más problemáticos y repitentes, como el único que los soportaría, una especie de bastión para los más denigrados y poco valorados. No sólo no los recibirían en otro colegio por sus antecedentes, también perderían el poder de negociación que sostienen con profesores y auxiliares.

\section{El Caso de la Institución Educativa Rígida}

En este segundo caso, el colegio tendrá como meta principal educar integralmente a sus alumnos en valores, para una sociedad nueva, humana y solidaria ${ }^{10}$. El colegio se despliega en una forma inclinada con dirección a un cerro, es decir, en la misma ladera, en donde los patios y salones se ven desplegados hacia arriba. Las aulas principales, la biblioteca y la sala de profesores se encuentran en la parte alta del colegio, desde donde se aprecia la totalidad de los patios, pudiendo observar si algún alumno se encuentra fuera del aula. A lo largo del colegio pueden apreciarse señalizaciones diversas que hacen referencia a valores, muchos de éstos de importancia religiosa, y se aprecian recomendaciones básicas de aseo y buen comportamiento. La arquitectura asimilaría características de vigilancia múltiple, asemejándose a un panóptico. A diferencia del colegio anómico, la "evasión" es impensable por parte de sus alumnos quienes temen a la autoridad docente, no encontrando a ninguno en las inmediaciones de los patios en horas académicas. Los basureros abundan por todo el colegio, por lo que no se encuentra basura en el patio. Los alumnos acuden al colegio con buzos, polos y casacas de la institución escolar. Por otra parte, la desconfianza hacia mi persona era mayoritaria por parte de los alumnos, quienes creían que mi presencia se debía a un recojo de información para futuras acusaciones. En efecto, la desconfianza reinaba, a diferencia del colegio anómico donde la confianza fluía sin ningún problema, producto de las facilidades con que contaban los alumnos para desplegar sus necesidades lúdicas.

Mundo de los auxiliares y mundo de los profesores. En la institución educativa un sólo auxiliar se encarga de que se cumpla la disciplina y el orden en el nivel escolar secundario debido al poco alumnado que existe. Los castigos

10 Proyecto Educativo Institucional 2001-2005 de dicha institución educativa. 
no serán físicos: los alumnos que lleguen tarde deberán correr alrededor del patio sin cesar, obligados por los gritos del auxiliar; bastará con algunas órdenes para que los alumnos continúen. Esta actividad se torna un tanto lúdica al surgir la broma interactiva entre unos y otros. Los alumnos interiorizan el mandato disciplinario, siendo difícil correr bajo el intenso sol de Huaycán.

El mundo de la vida del auxiliar no sólo se separará del mundo de la vida de los alumnos: las brechas territoriales entre ambos generarán prejuicios en el auxiliar, ya que éste no vive en Huaycán. Nos dice el auxiliar que a pesar de no repetir de año, los alumnos se caracterizan por su resignación, es decir por la carencia de resiliencia, "no responden" a las imposiciones docentes y educativas. Es el caso de un tipo de inclusión adaptativa - obediente (Bazán, 2005), el cual se refiere a la valoración de los jóvenes en la medida que hacen lo que los adultos necesitan, sin observarlos con necesidades y derechos independientes. Según explica el auxiliar, lo peor que puede hacer un alumno es decir alguna palabra soez o escupir al piso. Las diferencias entre el colegio anterior y éste son grandes y no son producto de un radical cambio de colectivos sociales adolescentes, sino de la influencia disciplinaria que pesa sobre ellos, que a lo sumo les permite lanzar un escupitajo en la tierra o emitir alguna grosería sin que lo oigan, o será castigado. Otra gran diferencia con el anterior caso es que el buzo y casaca del colegio no es ningún signo de poder o status juvenil, por el contrario representa el peligro de ser reconocidos y perseguidos por su propia institución educativa, la que no permitiría que sus alumnos cometan aquellas faltas perniciosas para la imagen institucional. A esto se añade la vergüenza de los alumnos ante sus pares, por ser alumnos de dicha institución educativa, el cual si bien es cierto es valorado como el mejor colegio estatal en Huaycán, el juicio emitido desde la opinión de los jóvenes liminales es el peor.

La institución educativa propiciará en los alumnos cierto sentimiento de desposeimiento (Goffman, 2001), el cual estará atento ante cualquier material ofensivo que pueda llevar el alumno, sea alcohol o cualquier otro. La institución vigilará al estudiante en todas sus actividades, tanto dentro como fuera del colegio, una clara semejanza con las ambiciones de una institución total. Se hace presente una tendencia absorbente o totalizadora, la cual estaría simbolizada por los obstáculos que se oponen a la interacción social de los estudiantes con sus pares. Los alumnos inclusive han perdido sus ambiciones territoriales al no tener un aula que les corresponda, pues a partir del año 2007 se implementó un sistema en el cual no existían los recreos, sino descansos de cinco a diez minutos aproximadamente, para luego cambiar de aula según el curso que correspondiera. Los jóvenes estudiantes perdían de este 
modo su derecho a recrearse, no podrían emplear su tiempo en actividades lúdicas extracurriculares como el deporte recreativo, al menos no al interior de la institución, la cual concibe así un sistema claramente rígido. Al llegar los alumnos al aula correspondiente después de los cinco minutos de descanso, encontrarán a un profesor esperándolos. No hay ya vacíos institucionales en los que puedan forzar rituales lúdicos de cualquier tipo. En los pocos minutos que tendrán para dirigirse a otra aula para el siguiente curso no podrán hacer nada fuera del control disciplinario, ya que serán vigilados desde lo alto del patio. Presenciamos una serie de vigilancias múltiples y entrecruzadas, de técnicas para sojuzgar al estudiante, a lo cual se añade una arquitectura que permitirá un control interior articulado (Foucault, 2004).

Si bien pueden conversar en el corto tiempo que tienen al cambiar de aula, serán pertinentemente vigilados por un profesor -al interior del aula que los estará esperando -o por un auxiliar- que los vigilará desde el panoptismo de la arquitectura institucional educativa. A diferencia del secreto generalizado y la no acusación por parte de los alumnos del colegio anómico, en esta institución rígida los profesores siempre se enterarán de quién será el infractor, en el caso de haberlo. Establecen una vigilancia que les permite crear condiciones en que la infracción de un individuo se destaca en singular relieve contra el fondo de sometimiento general, visible y comprobado (Foucault, 2004).

Las autoridades educativas no se arriesgarán a perder dichas condiciones. Por ejemplo, una de las decisiones que mayor rechazo produjo en los alumnos fue la de suspender los paseos recreativos fuera de la institución educativa. Esta condición eliminó a su vez los viajes de promoción del quinto año de secundaria. Ello se debería a que su rigidez educativa no podía permitir el descontrol de sus alumnos, no se pensaba renunciar al panoptismo. En un lugar de esparcimiento en donde se encuentran jóvenes de otros colegios, los espacios son abiertos, la disciplina se pierde y las tecnologías caducan. Se comprueba de este modo micropenalidades constantes, en las actitudes de mínimo desorden del alumnado. Estas son micropenalidades del tiempo, (al ser castigados por sus retrasos), de la actividad (al saltar y jugar), de la manera de ser (al silbar), de la palabra (al emitir groserías) y del cuerpo (al escupir, como gesto de suciedad).

Los alumnos estarán constantemente vigilados por los profesores, fuera y dentro del panóptico. Las principales faltas a considerar se limitan a ser responder de modo incorrecto a los profesores al momento de ser recriminados por alguna falta. Como sostiene un profesor los alumnos "saben con quién sí pueden y con quién no", esto gracias al empleo de tecnologías que limitan su capacidad de respuesta, de modo que en todo momento sepan que con esos 
profesores o autoridades diversas, no podrán maniobrar intento alguno de control. La institución rígida tendría como meta principal "cambiar" a los alumnos de costumbres que los alejan de los "valores supremos", para ello "mandarán" en sus aulas y harán lo necesario por encauzar a los alumnos y de este modo la disciplina "fabricará" individuos. Se trata de la técnica específica de un poder que concibe a los individuos a la vez como objetos y como instrumentos de su ejercicio (Foucault, 2004).

Prueba de ello es que en el colegio el pandillero no existe. Sólo se vislumbra aquel que desea proyectar una imagen violenta, para ser admirado por sus pares, pero no será capaz de sublevarse ante el orden disciplinario, por ello a lo sumo, ante los ojos de los profesores, es meramente un alumno "que se cree el bacancito"11, es decir sólo es una mofa y no una amenaza para el mundo de los profesores. En cuanto al estigma con que se concibe a la institución, uno de los sobrenombres despectivos era el de ser un "colegio de monjas", esto debido a que no existían jóvenes integrantes de grupos violentos. Dicho oprobio es muy duro en un contexto como Huaycán, en donde los estudiantes al salir del colegio deben volver a la cotidianeidad injusta de la violencia juvenil liminal que conquista las calles.

Si la institución pese a toda su rigidez no es capaz de "enderezar" al joven, o mejor dicho si falla en ser un operador para la transformación de un individuo, acusará el elemento familiar como el principal responsable de la "involución" de un alumno. Como señala uno de ellos, "si viene mal de casa, acá no se puede hacer nada". En efecto la imagen que proyecta el colegio en el imaginario de la comunidad es la de ser un colegio religioso que disciplina a sus alumnos y evita la perdición de los jóvenes, imponiéndoles valores que lo proyecten hacia una sociedad justa. Una institución rígida jamás fracasará, serán los factores familiares los que eviten una tarea total de su misión principal, ya que de ser ésta perfecta, se trataría invariablemente de una institución total.

Mundo de los estudiantes. Si hay algo que se aprecia en este colegio, son las subculturas que difieren de la juvenil liminal típicamente analizada en el caso anterior. Generan grupos de pares "punks", de "heavy metal" e inclusive con tendencias "emo"12. Una posible respuesta sería la carencia de

11 Testimonio de un profesor de educación secundaria.

12 Todas las mencionadas son subculturas juveniles con estilos que los diferencia del resto. Dicho estilo se vislumbra en el peinado, en el tipo de ropa que utilizan, los colores de ésta, así como brazaletes o marcadores sociales diversos que los identifiquen con pares similares a ellos. 
una plena socialización horizontal de estos jóvenes, debido al orden disciplinario impuesto. En el caso anterior serían vistos con desprecio por sentirse diferentes al resto, pero en la institución rígida esta solidaridad de pares no existe, y por ende tampoco existe la necesidad de enfrentar al que desea diferenciarse culturalmente en cuanto a modas y estilos. La institución rígida como tal, al imperar sobre buena parte de los alumnos, los empuja a elegir grupos de pares diferenciados de la mayoría existente en Huaycán. El rasgo más importante de esta individualidad se encuentra en la carencia de solidaridad colectiva, en donde todos se acusan mutuamente ante la autoridad educativa.

La carencia de legitimidad de la institución rígida. La mecánica de la institución rígida, como se comentó, emplea una microfísica del poder en donde no es necesario recurrir a la fuerza o a la violencia. El poder se basa en la imposición de valores necesarios para la transformación de sus estudiantes, incentivando una fidelidad hacia la institución, ocasionando que los propios alumnos acusen a los detractores que incumplan el orden instituido. Se trata de un poder en apariencia tanto menos "corporal" cuanto que es más sabiamente "físico" (Foucault, 2004). Para los administradores del panóptico escolar, lo esencial es que se sepa vigilado, por ello instigarán a los alumnos más problemáticos, “¿Qué has hecho?” dirán para aturdirlos y de este modo sean conscientes en todo momento de la existencia de unos ojos que los han de observar permanentemente. La imposición de los valores religiosos se logrará mediante la amenaza institucional, coaccionándolos contra su voluntad. Sin embargo tal como el testimonio manifiesta, los sujetos a modificar no serán fácilmente maniobrados, los estudiantes reconocerán dicho orden disciplinario y evitarán en muchas ocasiones escapar a dicho control:

Mucho control, nos incómoda, nos incomoda, dicen que el corte de cabello, que tiene que ser el polo de colegio. (Entrevista a profundidad, alumno de cuarto de secundaria).

La micro penalidad del cuerpo se hace presente: las modificaciones no sólo se limitarán al ámbito mental, la institución rígida reglamentará las formas visibles del cuerpo. Sin embargo los estudiantes no serán meros agentes pasivos del accionar disciplinario, sabrán aplicar una serie de estrategias, como la de escudarse en la carencia de recursos económicos capitalizando su pobreza económica. La "evasión" analizada en el caso anterior será imposible 
de imitar en la institución rígida, pero el ímpetu de alcanzarla no se perderá: evadirán todo tipo de actos disciplinarios desde las mínimas posibilidades que puedan construir. Lo que más desagrada del colegio a los alumnos serán los profesores, los auxiliares y la poca solidaridad de los compañeros, los que no guardarán secreto alguno que atente contra la institución rígida educativa.

Status y prestigio juvenil. Otro motivo que los alejaría de la institución educativa es el estigma con el que recriminan a sus estudiantes. No sólo pesará sobre ellos calificativo de ser provenientes de un "colegio de monjas", también será vergonzoso para estos jóvenes el llevar diariamente botellas de agua ${ }^{13}$. La situación se agrava cuando es necesario caminar sobre una superficie empinada llevando consigo una botella de más de dos litros de agua, siendo observado por diversos puñados de adolecentes. El imaginario de aquellos instigadores que mellan la seguridad del estudiante, reflejará a un joven sumiso, víctima de una institución rígida a la que obedecerá fielmente, convirtiéndose en un prosélito más de las monjas que gobiernan el estereotipo imaginado por los jóvenes críticos de esta institución. Algunos estudiantes desean salir del colegio e integrarse a colegios con mayor incidencia de pandillaje.

Esto se debe al prestigio que se consigue en dichas instituciones. El pertenecer a colegios con mayor índice de pandillaje permite a sus estudiantes proyectarse frente al gran auditorio juvenil que ve a este tipo de colegios como los de mayor rango y respeto a nivel de toda la comunidad. Les permite ser parte de la "farándula"14, es decir, ganar fama y por ende ser admirados por todos los jóvenes interconectados por redes juveniles. El aburrimiento es la característica principal con la que los estudiantes definen el colegio rígido. Esta categoría en el contexto juvenil liminal es el polo opuesto de lo que se entiende por "chonguero" que caracterizaba a la institución educativa anómica. Ningún entrevistado atinó a decir cuán divertido o "chonguero" podía ser el colegio rígido. Todos y todas se esforzaron por redundar en reclamos y quejas en torno a la rigidez con la que son controlados. Hay pocas posibilidades de un papel marcadamente activo desde los alumnos. Esta especie de

13 Las botellas de agua forman parte de un proyecto ecologista en donde riegan los diversos jardines que posee el colegio.

14 Éste es el término con que diversos estudiantes conocían a los jóvenes estudiantes que poseen mayor estatus en la comunidad gracias a su pertenencia a pandillas importantes. Éstos pueden ser tanto hombres como mujeres. 
panoptismo será el principio general de una nueva "anatomía política" cuyo objeto y fin no será la relación de soberanía sino las relaciones de disciplina (Foucault, 2004).

La pérdida de la identidad femenina es otro agravante que delibera mayor tensión en el alumnado. El buzo y la casaca designados para su uso diario homogenizan los sexos excluyendo la posibilidad de diferenciar la identidad sexual de cada género, esto limita las posibilidades de erotizar los cuerpos estudiantiles atrofiando la interacción simbólica de ambos sexos. El contraste de las faldas y las blusas femeninas, en contraposición a los pantalones y las camisas masculinas, crea una figuración masculina y femenina que construye su sexualidad a lo largo de la vida escolar del estudiante. Esta imposibilidad despertaría una continua tensión en alumnos y con especial intensidad en alumnas, e inclusive en padres de familia que insistirían en el uniforme escolar.

Profesores inapelables. A diferencia de la institución total, la institución educativa rígida admitirá que los estudiantes podrán encontrar múltiples referentes en incontables colegios, que conocerán pares de jóvenes que se burlarán de ellos, es decir, la institución rígida no podrá acceder a otros y deseados mundos de la vida. Como indica Mead (1990), el individuo se experimentará a sí mismo desde los puntos de vista de los otros miembros del mismo grupo social, adoptando las actitudes de los otros individuos hacia él dentro de un contexto de experiencia y conducta en que tanto él como ellos están involucrados. Por ende, tanto sus pares como él, en este mutuo involucramiento estarán en continua tensión entre lo aprendido en el colegio y lo que se aprende con los pares del vecindario y del propio colegio. Los docentes, brazos mecánicos del panóptico institucional, constantemente aconsejarán a los alumnos y desearán comprenderlos para crear una relación de confianza en ambos mundos de la vida. Pese a ello, según refieren los alumnos, cumplirán un rol instigador ante el mundo de la vida de los estudiantes:

Ni en un colegio estatal me llaman la atención, los profes te aconsejan, te aconsejan y aconsejan tanto, que cansa, que insisten, ¿por qué voy a cambiar? (Entrevista a profundidad, alumna de tercero de secundaria).

Las alumnas víctimas de la violencia doméstica no encontrarán en los profesores la atención necesaria. Una alumna sostiene lo siguiente: 
Cuando los profesores regañan nunca me miran a los ojos ... Acá no te aconsejan, lo único que hacen es gritarte, ya me tienen harta... En una ocasión la profesora Irma quería que le cuenten cosas y le dije que ya no estaba en ese grupo [pandilla femenina] y me acusó que yo era una chica maleada, movida ... Yo siempre respeté, nunca me peleé, nunca le respondí, [Ilora] sólo porque estaba en ese grupo le dijeron a mi mamá. (Entrevista a profundidad, alumna de segundo de secundaria).

Para muchas alumnas la intermediación de los profesores ocasiona un severo malestar, pues la desconfianza acumulada debido a la rigidez institucional hace difícil el contacto de ambos mundos de la vida. Si, en efecto, las restricciones de contacto ayudarían presumiblemente a mantener los estereotipos antagónicos (Goffman, 2001), ¿cómo explicar esta situación en una institución rígida en donde los profesores continuamente se acercan a los alumnos a "aconsejarles" y a "preguntarles" sobre lo que hacen? Como se explicó, ello se debería al gran cisma que existe entre ambos mundos de la vida, con valores eminentemente contradictorios, en donde los valores institucionales son supremos e inapelables. De ahí que el uso de los métodos confesionales se hace constante y vertical, desde los profesores hacia los alumnos.

\section{Conclusiones y Reflexiones}

El impacto de las tecnologías disciplinarias educativas ejercidas por los colegios estudiados tiene un papel fundamental en la vida estudiantil. En la institución educativa anómica, los jóvenes reforzarán sus interacciones clandestinas estudiantiles gracias al caldo de cultivo que les ofrecerá el colegio. Así, bautizarán a su colegio como el más "chonguero", gracias a que la vigilancia y el castigo no poseen poder suficiente en ellos. Por su parte en el colegio rígido, la microfísica del poder institucional educativo reducirá dramáticamente las interacciones clandestinas de los jóvenes alumnos. Se trata de lo opuesto a lo "chonguero", se trataría para sus estudiantes, de un colegio "aburrido". Sin embargo, aunque los alumnos sean sometidos, sus ansias de autodeterminación no cesarán. Su descontento será simbólico y discursivo. Desearán emular en todo momento a los jóvenes estudiantes de instituciones educativas anómicas, capaces de revelarse contra todo orden instituido. Sus estrategias de socialización buscarán siempre formas alternativas a las que les impongan los profesores. 
Los alumnos demuestran, así, sus ansias e ímpetus por tener una cuota de protagonismo al interior y fuera de sus escuelas. Una especie de revanchismo a la carencia de oportunidades y a la violencia doméstica que se vive en Huaycán. Son consideraciones que reflejan las ansias por demostrar que están "vivos", que son capaces de moldear el mundo a su favor gracias a sus energías y fuerzas innovadoras. Su mundo de la vida sería lo suficientemente capaz de erigirse a la par de los discursos adulto céntricos, a pesar de lo inconstante de su discurso y lo maleable de su accionar, pero no lo hacen individualmente. La solidaridad juvenil es lo más importante para ellos, es lo que hace "chonguera" su existencia, por ello la institución educativa anómica colma sus deseos. Por el contrario, el descontento hacia la institución educativa refleja la molestia que provoca en alumnas y alumnos la carencia de solidaridad estudiantil, debido a las tecnologías disciplinarias imperantes. Si bien son capaces de formarse adecuadamente, alejándose de las pandillas, estropean necesidades típicamente juveniles, como las del esparcimiento lúdico y el intercambio simbólico entre pares de su colegio, lo cual crea tensiones insalvables en aquellos estudiantes más expuestos a la violencia en sus lugares de residencia.

En los escenarios educativos analizados, es imposible vislumbrar marcadas separaciones entre lo racionalizado y lo lúdico en los jóvenes estudiantes de cada colegio. La investigación demuestra cómo las categorías binarias cercenan la complejidad existente en los jóvenes estudiantes, por lo que es importante reconocer las simultaneidades en las se desenvuelven. 


\section{Referencias}

Bazán, M. (2005). Protagonismo social de la juventud. Lima: IPEC.

Cánepa, M. A. (1990). Los jóvenes y el afecto. En O. Gonzáles et al. (Eds.) Juventud, crisis y cambio social en el Perú (pp. 163-164). Lima: IPEC.

Coulon, A. (1998). La Etnomedología. Madrid: Ediciones Cátedra S.A.

Foucault, M. (2004). Vigilar y Castigar. Buenos Aires: Siglo XXI.

Goffman, E. (1990). Estigma o la identidad deteriorada. Buenos Aires: Amorrortu.

Goffman, E. (2001). Internados. Buenos Aires: Amorrortu.

Guasch, O. (2002). Observación Participante. Cuadernos Metodológicos, 20. Madrid: Centro de Investigaciones Sociológicas (CIS).

Ibañez, J. (1986). El grupo de discusión: teoría y crítica. Madrid: Siglo veintiuno.

Macassi, S. (2001). Culturas Juveniles. Lima: Calandria.

Maffesoli, M. (1993). El conocimiento ordinario. Compendio de Sociología. México: Fondo de Cultura Económica.

Martín, M. (1993). La comunicación en la vida cotidiana. La fenomenología de Alfred Shütz. Pamplona: EUNSA - Universidad Navarra S.A.

Mead, G. H. (1990). Espíritu, persona y sociedad. México: Paidós Studio.

Merton, R. (1992) Teoría y estructura sociales. México: Fondo de cultura económica.

Mejía, J. (2003). De la construcción del conocimiento social a la práctica de la investigación cualitativa. Investigaciones Sociales, 11, 179-197. Lima: UNMSM /IIHS.

Molinari, T. (2002). Pautas teóricas integradas en la investigación Explorando las identidades políticas de los jóvenes en Lima. Investigaciones Sociales, 9, 257-262. Lima: UNMSM/ IIHS.

Morin, E. (1999). Epistemología de la Complejidad. París: Harmattan.

Recasens, A. (1999). Las barras bravas. Recuperado de http://www.facso. uchile.cl/publicaciones/biblioteca/docs/libros/barras.pdf

Schütz, A. (1974). Estudios sobre teoría social. Buenos Aires: Amorrortu Editores.

Schütz, A. (1993). La construcción significativa del mundo social. Barcelona: Paidós.

Turner, V. (1970). Simbolismo y ritual. Lima: PUCP. 